\title{
Clinical, biochemical, serological, histological and ultrastructural features of liver disease in drug abusers
}

\author{
I V D WELlER, D COHN, A SIERRALTA, M MITCHESON, M G R ROSS, \\ L MONTANO, P SCHEUER, AND H C THOMAS
}

From the Departments of Medicine, Histopathology and Medical Microbiology, Royal Free Hospital and the Drug Dependence Clinic, University College Hospital, London.

\begin{abstract}
SUMMARY Heroin abusers are frequently found to have abnormal liver function tests and hepatic histology. Hepatitis viruses A, B, and NANB, other drugs or drug contaminants and excessive alcohol consumption are factors thought to contribute. One hundred and sixteen heroin abusers attending a London treatment centre were studied. Sixty two $(53 \%)$ had a raised aspartate transaminase. This was not explained by current infection with hepatitis A and B, cytomegalo or Epstein-Barr viruses, excessive alcohol consumption ( $>80 \mathrm{~g} /$ day) or concomitant drug taking. Abnormal liver function tests were as frequent in those with markers of current or past $\mathrm{HBV}$ infection as those without and there was evidence that both HBV infection and the cause of the abnormal liver function tests were acquired in the first few years of intravenous drug abuse. Liver biopsies from eight patients showed chronic hepatitis with a mild lobular and portal inflammatory infiltrate, fatty change and prominent sinusoidal cells. Electron microscopy showed cytoplasmic trilaminar tubular structures and dense fused membranes in dilated endoplasmic reticulum. These clinical, biochemical, serological, and histological features would suggest a major role for NANB virus infection in the aetiology of hepatitis in heroin abusers.
\end{abstract}

Intravenous drug abusers are commonly found to have abnormal liver function tests and hepatic histology. Abnormal liver function tests, most commonly raised transaminases, have been found in 29 to $83 \%$ of drug abusers and histological abnormalities have included chronic persistent hepatitis, chronic active hepatitis, alcohol related liver disease, acute hepatitis and occasionally cirrhosis. ${ }^{1-5}$

The aetiological factors are largely unknown. A direct toxic effect of the drugs seems unlikely as morphine given to rhesus monkeys and human volunteers does not cause biochemical abnormalities of liver function. ${ }^{67}$ In addition, drug abusers changing from intravenous heroin to oral methadone replacement therapy show no significant improvement in liver function tests with time. ${ }^{8}$ Hepatitis B virus (HBV) infection is more common in intravenous drug abusers than in the normal population but chronic HBV infection only accounts for a small number of those with persistent

Address for correspondence: Dr H C Thomas, Department of Medicine. The Royal Free Hospital. Pond Street, Hampstead, London NW3.

Received for publication 21 June 1983 biochemical and histological abnormalities. ${ }^{3} 4$ 9-14 The incidence of antibodies to hepatitis A virus has been found to be no different from controls and chronic infection does not occur. ${ }^{4}$ Before the discovery of other transmissable causes of acute and chronic hepatitis, past infection with $\mathrm{HBV},{ }^{2} 312$ drugs other than heroin or possible drug contaminants, ${ }^{15}{ }^{16}$ talc granulomas ${ }^{17}$ and alcohol were all considered possible candidates responsible for the unexplained abnormalities of liver function tests and histology.

The aim of this study was to elucidate further the role of the hepatitis viruses and other agents in the cause of hepatitis in a clinic population of drug abusers.

\section{Methods}

PATIENTS

One hundred and sixteen drug abusers attending a treatment centre with a total population of approximately 175 were studied between December 1980 and August 1981. Patients attending for short periods of time and chronic intravenous drug 
abusers with inaccessible veins were excluded. Seventy four men and 42 women with a mean age of 28 years (range 19 to 42 years) were studied. One hundred and eight were intravenous heroin abusers, with a mean length of addiction of eight years (two and a half to 27 years), and eight were sniffers. The majority of patients were receiving oral methadone replacement therapy. Only six of the 74 men were homosexual. The medical notes in the clinic were reviewed for drug history, length of addiction, and past medical history including any previous liver function test results. In addition, patients were interviewed and answered a questionnaire for history of hepatitis, sharing of needles, tattoos, blood transfusion, concurrent drug use other than methadone, and alcohol consumption.

Blood was taken for routine liver function tests, (total bilirubin, alkaline phosphatase, aspartate amino transferase, total protein and albumin) and serum stored at $-20^{\circ} \mathrm{C}$. In five patients sufficient blood was obtained for serology but not for liver function tests. In those patients with abnormal liver function tests a second sample was sought to confirm the abnormality and this was obtained in 40 out of 61.

The stored serum was tested for $\mathrm{HBsAg}$, antiHBs, anti-HBc, anti-HAV by RIA (Austria II -125 , AUSAB, CORAB, HAVAB respectively, Abbott Laboratories). Those sera positive for anti-HAV were tested for IgM anti-HAV (HAVAB-M, Abbott). Antibodies to delta agent were detected by a solid-phase blocking RIA (Dr M Rizetto, Turin). ${ }^{18}$ Antibodies to cytomegalovirus were detected by standard complement fixation test, performed in microtitre plates, using cytomegalovirus antigen from the Public Health Laboratory Service at Colindale. Selected sera with midrange titres or rising titres were also tested for IgM class antibodies to cytomegalovirus, using the method described by Kangro $^{19}$ (Dr Paul Griffiths, St Bartholomew's Hospital, London). A standard indirect immunofluorescence test was used to detect IgM class antibody to Epstein-Barr virus using Burkitt lymphoma cells ${ }^{20}$ (Dr R Pilsworth, PHLS, Chelmsford). One hundred and sixty seven sera from 116 patients were analysed in a recently reported solid phase radioimmunoassay for NANB associated antigen. ${ }^{21}$ We were unable to test for antibody because of a shortage of the antigen.

Eight asymptomatic HBsAg negative patients with demonstrated abnormalities of liver function tests for a mean of 4.4 years (range two months to nine years) consented to percutaneous liver biopsy. Five had serological evidence of past HBV infection and three did not. Paraffin sections were stained by haematoxylin and eosin, Gordon and Sweets' reticulin method, Shikata's orcein stain, the periodic acid Schiff stain after amylase digestion and Perls' method for iron. Seven of the eight cases had liver tissue taken for electron microscopy. This was fixed in 3\% (cacodylate buffered) glutaraldehyde and postfixed in $1 \%$ osmium tetroxide. The tissue was embedded in Lemix and ultrathin sections were stained with uranyl acetate and Reynolds lead citrate. As a control liver tissue from six cases of chronic hepatitis B were similarly prepared. Ultrathin sections were examined under a Philips 201 electron microscope for nuclear and cytoplasmic changes such as tubular and dense membranous structures. In five of the eight cases a portion of liver was snap frozen in OCT and examined for HBV markers by immunofluorescence. $\mathrm{HBsAg}$ was detected by indirect immunofluorescence using an $\mathrm{IgG}_{1}$ class monoclonal antibody and tetraethylrhodamine isothiocyanate conjugated goat antimouse $\mathrm{IgG}_{1}$ as a second layer. $\mathrm{HBcAg}$ was detected by direct immunofluorescence using an FITC conjugated human antiserum to $\mathrm{HBcAg}$.

\section{Results}

Sixty one out of 111 patients had a raised aspartate aminotransferase. In 25 patients this was less than twice the upper limit of normal. Bilirubin and alkaline phosphatase were raised with aspartate transaminase in seven and 12 patients respectively. Total protein and albumin were normal in all patients.

Seventy two per cent of the patients had some marker of hepatitis B virus infection (Table). Sixty per cent had anti-HBs and 5\% HBsAg indicating past and current infection respectively. Eight per cent had anti-HBc alone. Of the six patients who were $\mathrm{HBsAg}$ positive, two had an acute hepatitis and four were carriers having been positive for more than six months. Of the $56 \%$ who had anti-HAV none had serological evidence of recent infection.

Table Hepatitis $A$ and $B$ serology in 116 drug abusers

\begin{tabular}{lcc}
\hline Marker & No & positive (\%) \\
\hline HBsAg & $6^{*}$ & 5 \\
anti-HBs alone & 3 & 3 \\
anti-HBc alone & 9 & 8 \\
anti-HBc + anti-HBs & 66 & 60 \\
Total with HBV markers & 84 & 72 \\
Anti-HAV & 65 & 56 \\
IgM-anti-HAV & 0 & 0 \\
Total with anti-HAV & 65 & 56 \\
\hline
\end{tabular}

* Two had acute hepatitis, four had been $\mathrm{HBsAg}$ positive for more than six months. 
There was no significant difference in the incidence of HAV or HBV markers between the sexes. Three of 43 abusers had anti- $\delta$. One was an HBsAg carrier with anti- $\delta$ titres $>1$ in $10^{3}$ probably indicating current infection. He refused liver biopsy. Two had anti- $\delta$ titres $<1$ in $10^{3}$ and both had anti-HBC and anti-HBs probably indicating past infection with $\mathrm{HBV}$ and $\delta$.

There was no evidence of current cytomegalovirus infection in any of the patients in this study. Thirty out of the 116 patients with a titre of $<8$ had no evidence of previous infection. The remaining patients had evidence of a past and probably remote cytomegalovirus infection with the antibody titres being distributed as follows: $42 / 116$ had a titre of 8 , $16 / 116$ a titre of $16,17 / 116$ a titre of $32,8 / 116$ a titre of 64 and three a rising titre. Although a rise in antibodies was detected in three patients, the rises were only a four fold increase and the titres were not consistent with a recent cytomegalovirus infection. Furthermore IgM antibody to cytomegalovirus was not detected in the convalescent sera of any of these three patients nor in any of those patients with a titre of 64 .

Sera from 66 patients taken at random were examined for Epstein-Barr virus specific antibodies. IgM class antibody was not detected in any patient.

Only four of 116 patients $(3.4 \%)$ were positive for a NANB associated antigen and three of these had normal liver function tests. None of these patients had liver biopsies.

Abnormalities in liver function tests were as frequent in patients with markers of hepatitis B virus infection as in those without $(60 \%$ and $52 \%$ respectively) and as frequent in those with markers of past HAV infection as in those without $(53 \%$ and $57 \%$ respectively). There was no trend towards an increasing incidence of HBV markers or abnormal liver function tests with the length of intravenous drug addiction prior to entry into the study (Fig. 1).

From examination of their clinical records and the questionnaire $45 \%(49 / 110)$ gave a history of acute hepatitis and $12 \%$ (seven) of these had more than one episode. Eighty two per cent of patients $(69 / 84)$ admitted to sharing needles, $16 \%(13 / 81)$ had been tattooed and $13 \%(10 / 80)$ had received blood transfusions. Nine per cent gave a history of drinking greater than 80 grams of alcohol, and $18 \%$ a history of more than 60 grams daily. Sixty two per cent $(39 / 63)$ had been taking some drug, often several, for therapeutic purposes in the previous three months. Twenty seven were taking one for pain (aspirin 10, paracetamol nine): 15 were taking tranquilisers (Valium six): 14 were taking antibiotics (metronidazole three, ampicillin 3, erythromycin 1) and nine were on oral contraceptives.

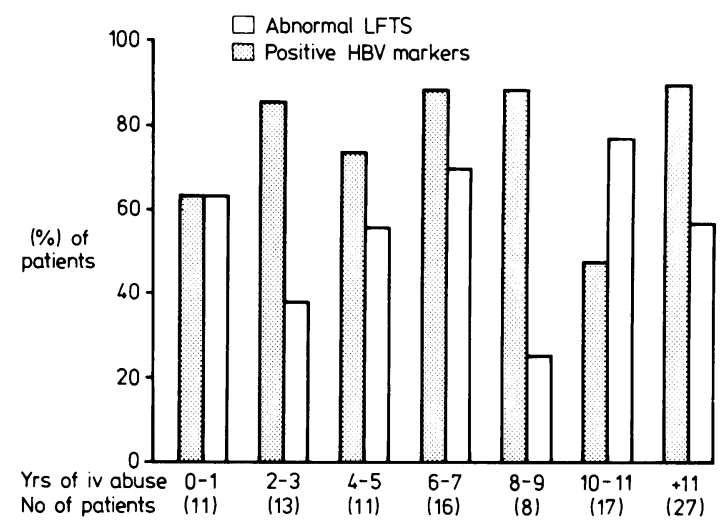

Fig. 1 Length of intravenous drug abuse, $H B V$ markers and abnormal liver function tests in 103 abusers.

\section{MICROSCOPY}

Light microscopy showed an overall appearance of a mild lobular and portal inflammatory lesion with some fatty change and prominent sinusoidal cell activity. One biopsy showed lobular hepatitis indistinguishable from an acute hepatitis. Four of the biopsies showed features of chronic persistent hepatitis with mild lobular hepatic change. Two had an appearance of chronic persistent hepatitis alone and there was one biopsy with chronic active hepatitis associated with cirrhosis. None of the biopsies showed light microscopic changes of cholestasis. Focal cytolytic necroses were more frequently observed than acidophilic (apoptotic) bodies. Birefringent needle shaped foreign material was seen in macrophages in the portal tracts of only one biopsy.

Electron microscopy revealed only two cases in which nuclear particles $(27-30 \mathrm{~nm}$ diameter) were present. Cytoplasmic trilaminar tubular structures (Fig. 2) were seen in two biopsies one of which also contained the nuclear particles. In all seven cases scattered hepatocytes contained numerous dense fused membranes in dilated endoplasmic reticulum (Figs. 3 and 4). These were associated with normal bile canaliculi showing no dilatation or loss of microvilli. Five of six chronic hepatitis B control cases contained no such cytoplasmic structures. One from this group, however, did and on closer questioning the patient also admitted to a history of drug abuse. None of the biopsies contained HBV antigens by immunofluorescence.

\section{Discussion}

Fifty five per cent of the drug abusers had abnormal liver function tests usually a mild rise of aspartate 
Fig. 2 Electron microscopy showing cytoplasmic trilaminar tubular structure (arrow) $\times 57000$ (original magnification).

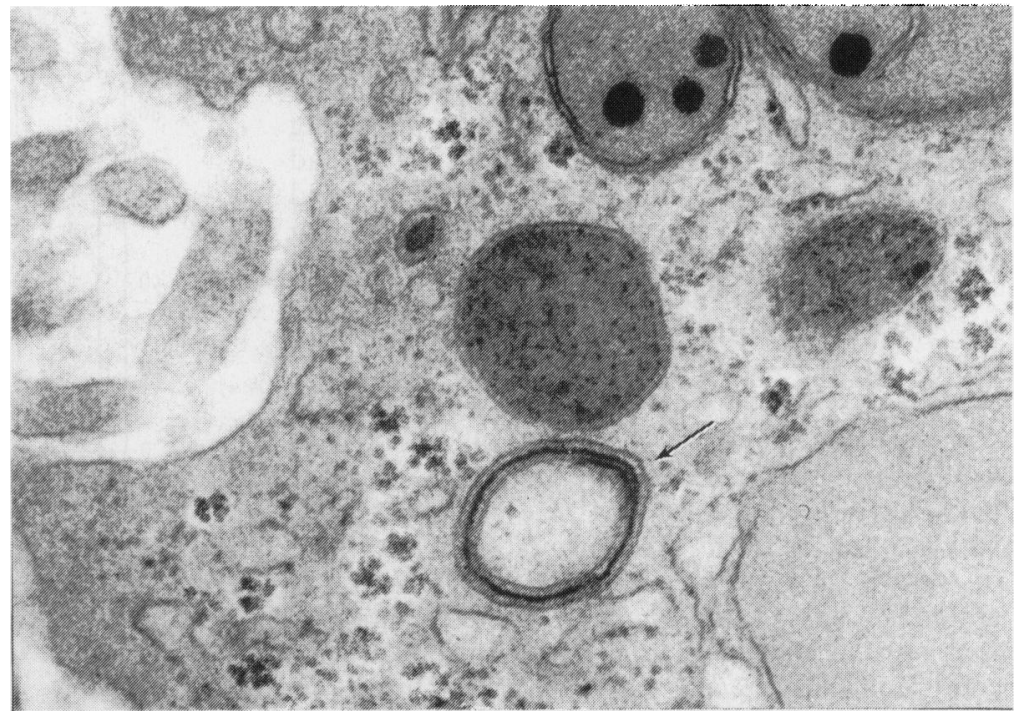

amino transferase. We have confirmed a high prevalence of hepatitis B virus infection among intravenous drug abusers, with $57 \%$ having antiHBs and anti HBc suggesting past infection. Those with anti-HBc alone may have had a recent subclinical acute $\mathrm{B}$ hepatitis being in the serological window between loss of HBsAg and the development of anti-HBs. Five per cent had evidence of current infection. This high prevalence of HBV infection is presumably related to the habit of sharing needles to which $82 \%$ of our patients admitted. Interestingly also, $13 \%$ and $16 \%$ of our patients had a past history of blood transfusions or tattoos respectively. There was no relationship between the prevalence of $\mathrm{HBV}$ infection and duration of addiction, suggesting that the infection is acquired early, perhaps in the first two years of intravenous drug abuse. This is in accord with the finding that the majority of intravenous drug abusers with acute hepatitis had been addicted for less than a year. ${ }^{22}$ As in other studies, however, ${ }^{4}{ }^{112}$ abnormalities in liver function tests were as frequent
Fig. 3 Electron microscopy showing numerous intracytoplasmic fused membranes (note normal bile canaliculi, arrow) $\times 9300$ (original magnification).

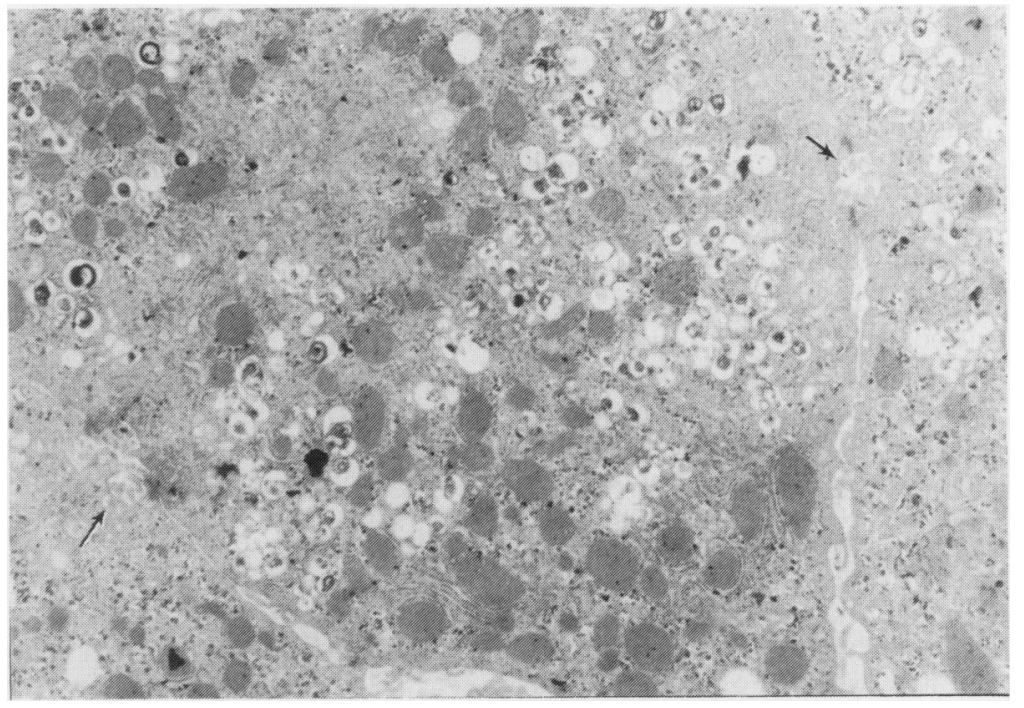


Fig. 4 Electron microscopy with higher magnification of intracytoplasmic dense fused membranes $\times 87000$ (original magnification).

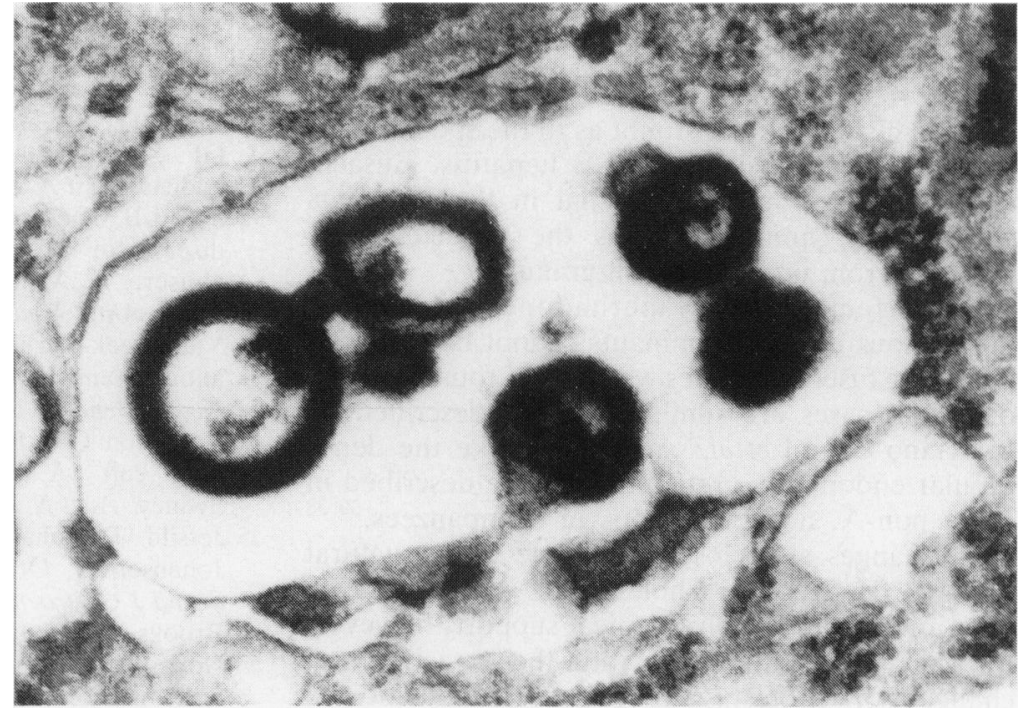

in patients with markers of $\mathrm{HBV}$ infection as in those without; $60 \%$ and $52 \%$ respectively. Furthermore, the majority of those with markers, had evidence of past infection. It is therefore, unlikely that HBV infection was the major cause of abnormal liver function tests in our patients.

Fifty six per cent of our patients had past hepatitis A virus infection. This figure is slightly higher than that reported by Boughton ${ }^{4}$ and much higher than that of a normal population of a similar age group and social class in London $(\simeq 30 \%) .{ }^{23}$ This might be explained by the frequent travel, as part of the drug culture, to countries with a high prevalence of HAV infection. Acute infection with hepatitis A virus, however, does not explain the abnormal liver function test in our patients and abnormalities of liver function tests were as frequent in those with markers of past HAV infection as in those without. Furthermore, current infection with $\delta$ agent, CMV or EBV viruses, excessive alcohol consumption or the concurrent taking of hepatotoxic drugs does not explain the high prevalence of abnormal liver function tests.

The NANB associated antigen has been found in $40 \%$ of cases of acute postinfusion NANB hepatitis in haemophiliacs. ${ }^{21}$ It $^{\prime}$ was also found in $24 \%$ (five out of 17) of sporadic acute NANB hepatitis (four of whom were drug addicts) and in $19 \%$ of patients attending a haemophiliac centre. In our patients, however, the prevalence of this antigen is similar to that in controls, patients with non-viral liver disease and miscellaneous non-hepatic diseases (0-4\%). In our study only two of the 62 patients with raised transminases had a clinical acute hepatitis and in both this was due to HBV infection. The majority of patients had a persistent mild rise of transaminase and those biopsied had a chronic hepatitis. It is possible that the NANB associated antigen which is present in acute infection in haemophiliacs, was present in low concentration in some of our patients and not detected by the assay. Alternatively, as there is more than one parenterally transmitted NANB virus as shown by cross challenge experiments in chimpanzees, ${ }^{2425} 31$ it is conceivable that the predominant type of NANB hepatitis occurring in drug addicts is different to that seen in haemophiliacs receiving factor VIII concentrates.

There was no relationship between the prevalence of abnormal liver function tests and duration of addiction, suggesting as with $\mathrm{HBV}$ infection, that whatever agent is responsible for the abnormality, it is encountered in the first two years of intravenous drug abuse.

The light microscopic appearance corresponds to that described in other series of chronic non- $A$, non-B hepatitis. ${ }^{26-28}$ Changes in the liver, consistent with these recent descriptions, were described as early as $1973 .^{29}$

With electron microscopy intranuclear particles have been described in chimpanzees and humans with acute and chronic NANB hepatitis. ${ }^{30-34}$ Nuclear particles were observed in only two of our eight cases. This may well be due to sampling as the reported frequency of finding such particles in human tissue is rather small - one in 50 nuclei. ${ }^{35}$ The size of the particles and the morphological 
appearance bears close similarity to normal chromatin particles, in particular interchromatin granules, which have a mean diameter of 20-25 $\mathrm{mm} .{ }^{36}$ This raises some doubt as to the specificity of such particles in non-A, non-B hepatitis. Busachi et $a l,{ }^{37}$ however considered that in their patients with non-A, non-B hepatitis the particles were different from interchromatin granules.

An effect due to methadone, heroin or intravenous drug contaminants cannot be excluded but dense fused mebranes which were found in all of our eight cases are similar to those described by Marciano-Cabral et $a l,{ }^{35}$ and not unlike the dense tubular endoplasmic reticulum change described in acute non-A, non-B hepatitis in chimpanzees. ${ }^{30} 38$ Such changes also closely resemble ultrastructural features described in cholestasis. ${ }^{39}$ There was no light microscopic or biochemical support, however, for this in our study. In addition the ultrastructural changes of cholestasis characteristically include dilatation of the bile canaliculus and loss of the lining microvilli. These features were absent in our cases. The dense fused membranes may represent membrane degeneration with phospholipid accumulation. The similarity of these structures to those due to sphingomyelin accumulation in Niemann-Pick disease is very striking. ${ }^{40}$ The trilaminar tubular structures in the endoplasmic reticulum, in two of our cases, somewhat resemble structures reported in hepatocellular cytoplasm in man, chimpanzees, and tamarins. ${ }^{31} 373841-43$

With no evidence of a casual role for hepatitis $A$ or $\mathrm{B}$ or other viruses in the abnormal liver function tests in our patients and the absence of other factors, the possibility of NANB virus infection must be considered. Other studies have shown a high proportion of intravenous drug abusers among patients with acute NANB hepatitis admitted to an infectious disease hospital. ${ }^{44}$ In our patients the mild abnormalities of liver function tests and the similarity of the light and electron microscopic findings to those described in the NANB virus literature lend support to this suggestion. Confirmation must await the development of serological tests for NANB infection.

IVDW was an MRC Training Fellow and is now lecturer in Genito-Urinary Medicine at the Middlesex Hospital Medical School, London. DC was on an Australian Commonwealth postgraduate study award and supported by the Peter Samuel Royal Free Fund and by the Stanley Thomas Johnson Foundation. LM was supported by the Mexican Research Council and HCT is a Senior Wellcome Fellow.

\section{References}

1 Ireton HJC, Gust ID, Moon WJ, Lehman N, Stening GF, Smallwood R. The covert liver disease of drug addicts. Aust N Z J Med 1974; 4: 444-9.

2 Seef LB, Kiernan T, Zimmerman HJ, et al. Hepatic disease in asymptomatic parenteral narcotic drug abuser. A Veterans Administration collaborative study. Am J Med Sci 1975; 270: 41-7.

3 Van Beek-Verbeck. The presence of hepatitis B antigens and antibodies in the blood of drug addicts. Ned T Geneesk 1979; 123: 1144-7.

4 Boughton CR, Hawkes RA. Viral hepatitis and the drug cult. A brief socioepidemiological study in Sydney. Aust N Z J Med 1980; 10: 157-61.

5 Jersild $\mathrm{T}$, Johansen $\mathrm{C}$, Balslov JT, Hojgaard $\mathrm{K}$, Johansen A, Ott C. Hepatitis in young drug users. Scand J Gastroenterol 1970; suppl 7: 79-83.

6 Brooks FP, Deneau GA, Potter HP, Reheinhold JG, Norris RF. Liver function tests in morphine-addicted and in non-addicted Rhesus monkeys. Gastroenterology 1963; 44: 287-90.

7 Gorodetzky CW, Sapira JD, Jasinski P, Martin WR. Liver disease in narcotic addicts. The role of the drug. Clin Pharmacol and Therap 1968; 9: 720-4.

8 Kreek MJ, Dodes L, Kane S, Knobler J, Martin R. Long term methadone maintenance therapy: effects on liver function. Ann Intern Med 1972; 77: 598-602.

9 Stimmel B, Vernace S, Schaffner F. Hepatitis B surface antigen and antibody. A prospective study in asymptomatic drug abusers. JAMA 1975; 234: 1135-8.

10 Whaley WH, Galambos JT. Race and risk of hepatitis in narcotic addicts. Am J Dig Dis 1973; 18: 460-6.

11 Robinson MG, Ream NW, Conrad ME, Ginsberg AL. Prevalence of hepatitis B antigen and antibody among heroine users in Vietnam. Gastroenterology 1974; 66: A111/765.

12 Miller DJ, Kleber H, Bloomer JR. Chronic hepatitis associated with drug abuse: significance of hepatitis B virus. Yale J Biol Med 1979; 52: 135-40.

13 Blanck RR, Ream N, Conrad M. Hepatitis B antigen and antibody in heroin users. Am J Gastroenterol 1979; 71: 164-7.

14 Arnold W. The importance of hepatitis B infection in drug addicts. European Symposium on Hepatitis B. Hepatology 1981; 2: 542.

15 Iwarson S, Lundin P, Homgreen J, Hermodsson S. Multiple attacks of hepatitis in drug addicts. Biochemical immunochemical and morphologic characteristics. J Infect Dis 1973; 127: 544-50.

16 Barrett PVD, Boyle JD. "Hippie hepatitis": the possible role of methamphetamine in chronic active hepatitis. Gastroenterology 1968; 54: 1219.

17 Kyung-Whan M, Gyorkey F, Gain D. Talc granulomata in liver disease in narcotic addicts. Arch Pathol 1974; 9: 331-5.

18 Rizzetto M, Shih JWK, Gerin JL. The hepatitis B virus associated $\delta$ antigen: isolation from liver, development of solid-phase radioimmunoassays for $\delta$ antigen and anti- $\delta$ and partial characterisation of $\delta$ antigen. $J$ Immunol 1980; 125: 318-24. 
19 Kangro HO. Evaluation of a radioimmunoassay for IgM class antibodies against cytomegalovirus. BrJ Exp Pathol 1980; 61: 512.

20 Edwards JMB, McSwiggan DA. Studies on the diagnostic value of an immunofluorescence test for E.B. virus specific IgM. J Clin Pathol 1974; 27: 647-51.

21 Luo KX, Karayiannis P, Bamber M, Kernoff P, Thomas HV, Sherlock S. Prevalence of a non-A, non-B associated antigen/antibody system detected by radioimmunoassay in acute and chronic liver disease. $\mathrm{J} \mathrm{Med}$ Virol 1983 (In press).

22 Cherubin CE, Hargrove RL, Prince A. The serum hepatitis related antigen ( $\mathrm{SH})$ in illicit drug users. $A m J$ Epidemiol 1970; 91: 510-7.

23 Damjanovic V, Ross M, Brumfitt W. Studies on antibody to hepatitis. A virus in children and adults in London. Infection 1979; 7: 267-72.

24 Hollinger FB, Mosley JW, Szmuness W, Aach RD, Peters RL, Stevens C. Transfusion-transmitted viruses study: experimental evidence for two non-A, non-B hepatitis agents. $J$ Infect Dis 1980; 142: 400-7.

25 Yoshizawa $\mathrm{H}$, Itoh Y, Iwarkiri S, et al. Demonstration of two different types of non-A, non-B hepatitis by re-injection and cross challenge studies in chimpanzees. Gastroenterology 1981; 81: 107-13.

26 Bamber M, Murray AK, Weller IVD, et al. Clinical and histological features of a group of patients with sporadic non-A, non-B hepatitis. J Clin Pathol 1981; 34: $1175-80$.

27 Bamber M, Murray A, Arborgh BAM, et al. Short incubation non- $A$, non-B hepatitis transmitted by factor VIII concentrate in patients with congenital coagulation disorders. Gut 1981; 22: 854-9.

28 Phillips MJ, Powell S. Modern aspects of the morphology of viral hepatitis. Hum Pathol 1981; 12: 1060-84.

29 Rosenblate HJ, Eisenstein R, Baldwin D, Homes AW. Non viral hepatitis in drug addicts. Arch Pathol 1973; 95: 18-21.

30 Jackson D, Tabor E, Gerety RJ. Acute non-A, non-B hepatitis: specific ultrastructural alterations in endoplasmic reticulum of infected hepatocytes. Lancet 1979; I: 1249-50.

31 Shimizu YK, Feinstone SM, Purcell RH, Alter HJ, London WT. Non-A. non-B hepatitis: ultrastructural evidence for two agents in experimentally infected chimpanzees. Science 1979; 205: 197-200.
32 Gmelin K, Kommerell B, Walherr R, Ehrlich BV. Intranuclear virus-like particles in a case of sporadic non-A, non-B hepatitis. J Med Virol 1980; 5: 317-22.

33 Grimaud JA, Peyrol S, Vituiski L, Chevallier-Queyron $P$, Trepo C. Hepatic intranuclear particles in patients with non-A, non-B hepatitis. $N$ Engl J Med 1980; 303: 818-9.

34 Bamber M. Murray AK, Lenvin J, Thomas HC, Sherlock S. Ultrastructural features in chronic non-A. non-B (NANB) hepatitis: a controlled blind study. $J$ Med Virol 1981: 8: 267-75.

35 Marciano-Cabral R, Rublee KL, Carithers RL, Galen EA, Sobieski TJ, Cabral GA. Chronic non-A, non-B hepatitis: ultrastructural and serologic studies. Hepatology 1981; 1: 575-82.

36 Puvion E, Mayne G. Interchromatin granules. In Busch H, ed. The cell nucleus "nuclear particles" Part A. Academic Press 1980; 85-90.

37 Busachi CA, Realdi G, Alberti A, Badiali-De Georgi $L$, Tremolada $F$. Ultrastructural changes in the liver of patients with chronic non-A, non-B hepatitis. $J$ Med Virol 1981; 7: 205-12.

38 Yoshizawa $\mathrm{H}$, Itoh $\mathrm{Y}$, Iwarkiri S et al. Non-A, non-B (Type 1) hepatitis agent capable of inducing tubular ultrastructures in the hepatocyte cytoplasm of chimpanzees: inactivation by formalin and heat. Gastroenterology 1982; 82: 502-6.

39 Schaff $Z$ and Lopes K. Cholestasis. In Johannessen JV, ed. Electron microscopy in human medicine vol 8. The liver. McGraw Hill, 1979: 80-8.

40 Metabolic disorders. In Johanneson JV, ed. Electron microscopy in human medicine. Vol. 8. The liver. McGraw Hill 1979: 27-9.

41 De Wolf-Peters C, De Vos R, Desmet V, et al. Human non-A, non-B hepatitis: ultrastructural alterations in hepatocytes. Liver 1981; 1: 50-5.

42 Tsiquaye KN, Amini S, Kessler H, Bird RG, Tovey G, Zuckerman AJ. Ultrastructural changes in the liver in experimental non-A, non-B hepatitis. Br J Exp Pathol 1981; 62: 41-51.

43 Karayiannis P. Scheuer PJ, Bamber M. Cohn D. Hurn BAL, Thomas HC. Experimental infection of Tamarins with human non-A, non-B hepatitis virus. J Med Virol 1983; 11: 251-6.

44 Bamber M. Thomas HC. Bannister B. Sherlock S. Acute A, B, and non-A non-B hepatitis in a hospital population in London. Gut 1983: 24: 561-4. 